\title{
Consciousness raising tasks for the learning of grammar in high school English language classrooms
}

Estrategias didácticas para concientización de elementos formales de la Gramática Inglesa en Educación Secundaria

\section{Volumen 18, Número 3 \\ Setiembre-Diciembre}

pp. 1-27

\section{Este número se publica el 1 de setiembre de 2018 \\ DOI: https://doi.org/10.15517/aie.v18i3.34330}

\author{
Jean Pool Salazar Miranda \\ Estefany Quesada Fallas \\ Massiel Rojas Blanco \\ Dayana Barrantes Salas \\ Luis Diego Madrigal Alfaro \\ José Miguel Vargas Vásquez
}

Revista indizada en REDALYC, SCIELO

Revista distribuida en las bases de datos:

LATINDEX, DOAJ, REDIB, IRESIE, CLASE, DIALNET, SHERPA/ROMEO, QUALIS-CAPES, MIAR

Revista registrada en los directorios:

ULRICH'S, REDIE, RINACE, OEI, MAESTROTECA, PREAL, CLACSO 


\title{
Consciousness raising tasks for the learning of grammar in high school English language classrooms \\ Estrategias didácticas para concientización de elementos formales de la Gramática Inglesa en Educación Secundaria
}

\author{
Jean Pool Salazar Miranda' \\ Estefany Quesada Fallas ${ }^{2}$ \\ Massiel Rojas Blanco 3 \\ Dayana Barrantes Salas ${ }^{4}$ \\ Luis Diego Madrigal Alfaro 5 \\ José Miguel Vargas Vásquez ${ }^{6}$
}

\begin{abstract}
From the pedagogical mediation of English grammar, many instructors heavily rely on textbooks, but many textbooks promote memorization instead of conscious use of grammar. Based on this premise, this article aims to evaluate the effectiveness of Consciousness Raising Grammar Tasks as a strategy to teach three verb tenses in English. The study followed a mixed method approach with a component of classroom action research, where the researchers taught the simple past, the past continuous, and the present perfect to a group of ninth graders in the Reading and Writing class at the Palmares Bilingual High School, Alajuela, Costa Rica within the tasks studied. The data analyzed consisted of the mean scores of the tasks (pre-post-delayed) and the triangulation of the perspectives of students, cooperating teacher, and the researchers. The results of the mean scores revealed an improvement in all the tenses in the post test and that most scores were retained in the delayed test. Through the triangulation of perspectives, the researchers identified that these tasks were positively assessed and that they encouraged active participation and critical thinking on the part of students. The conclusions pointed to a possible cumulative effect of the implementation of the tasks and to a need for exploring the impact of these tasks on the students' ability for self-monitoring in more independent practice.
\end{abstract}

Key Words: english, teaching grammar, secondary education.

Resumen: Desde la mediación pedagógica de la gramática inglesa, muchos profesores dependen en gran medida de libros de texto, pero muchos de estos promueven la memorización en lugar del uso consciente de la gramática. Basado en esta premisa, este artículo pretende evaluar la efectividad de las actividades para la concientización formal de elementos lingüísticos para el aprendizaje de la gramática como una estrategia para enseñar tres tiempos verbales en inglés. Este estudio siguió un diseño de método mixto con un componente de investigación-acción donde los investigadores enseñaron pasado simple, pasado continuo y presente perfecto a un grupo de estudiantes de noveno año en clases de escritura y lectura en el Colegio Bilingüe de Palmares, Alajuela, Costa Rica a través de las actividades investigadas. Los datos analizados consistieron en los puntajes promedio de las actividades (examen previo, posterior y final) y la triangulación de las perspectivas de los estudiantes, el docente cooperador y los investigadores. Los resultados de los promedios revelaron una mejora en todos los tiempos en la prueba posterior y la mayoría de las puntuaciones se mantuvieron en la prueba final. Mediante la triangulación de perspectivas, los investigadores identificaron que estas actividades fueron positivas y que alentaron la participación activa y el pensamiento crítico de los estudiantes. Las conclusiones indicaron un posible efecto acumulativo de la implementación de las actividades y la necesidad de explorar el efecto de estas actividades en la habilidad de los estudiantes para auto monitorearse en una práctica más independiente.

Palabras clave: inglés, gramática, educación secundaria

\footnotetext{
${ }_{1}^{1}$ Centro Nacional de Idiomas, Sede de Grecia, Costa Rica. Dirección electrónica: jeanpool-09@hotmail.com

2 Discovery Language Academy, Palmares, Costa Rica.Dirección electrónica: steff.q18@gmail.com

${ }^{3}$ Asesor Independiente. Dirección electrónica: masi3227@hotmail.com

${ }^{4}$ Ministerio de Educación Pública, Matina, Costa Rica. Dirección electrónica: daya15m@hotmail.es

${ }^{5}$ Centro Cultural de Idiomas, Sede Heredia, Costa Rica. Dirección electrónica: diego-16170@hotmail.com

${ }^{6}$ Universidad de Costa Rica, Sede de Occidente, Costa Rica.Dirección electrónica: jsmgvargas@gmail.com
}

Artículo recibido: 27 de marzo, 2018

Enviado a corrección: 12 de junio, 2018

Aprobado: 13 de agosto, 2018 


\section{Introduction and Justification}

During the last decades, many English textbooks have been created with grammar as the main focus of instruction. English teachers have the possibility of choosing from many textbooks to use as a guide to plan their lessons. In some cases, high school teachers are expected to follow the units and activities of a given book very closely. The problem arises when English teachers rely too heavily on textbooks or become dependent on them, but are not capable of adapting the proposed activities to the needs of their group. The prevalence of these conditions in secondary schools was identified in a survey carried out by the researchers in a group of public and private high schools.

To address this deficiency, Consciousness Raising Tasks (CRTs) are proposed as a tool to help teachers in grammar instruction and students to become fully aware of the target grammar feature. CRTs are designed to provide students with the possibility of understanding grammatical rules by themselves. As Roza (2014) has stated "Consciousness Raising is an approach that aims to help students to be aware of determined features; its main idea is to make students notice something they might not notice on their own, which will help them to develop analytical skills" (p. 3). One of the main goals of his project is to determine the potential effectiveness of these tasks in the learning process of English verb tenses.

A series of authors have contributed to the definition of Consciousness Raising (CR) in second and foreign language learning. For instance, Widodo (2006) developed a series of steps that aim to help students to become aware of grammar use and to achieve $\mathrm{CR}$. $\mathrm{He}$ established five steps to teach grammar based on his own experience with the inductive and deductive approach, namely: Building up students' knowledge of the rule, eliciting functions of the rule, familiarizing students with the rule and use through exercises, checking student's comprehension, and expanding students' knowledge. In addition, Ellis (2002) provided principles to follow when implementing CRTs. Among these principles are: focusing only on one grammar feature at a time, providing data to exemplify the use of the grammatical features, and asking learners to describe the rule by themselves. Moreover, learners have to focus more on the meaning of the grammar structure than on the form or its rule. In addition, the continued used of a structure facilitates its acquisition. Finally, providing feedback to the students is essential in the process. Azizifar, Babaei, Jamalinesari, and Gowhary (2015) proposed two procedures that must be taken into account to correctly apply the principles of CRTs: directing students' attention to a specific feature and encouraging students to create connections to find the rule behind the use of that feature to increase their analytical thinking 
and, consequently, their language learning. In other words, these steps, principles, and procedures were the base for the development of the CRTs.

When conducting the review of literature for this project, the researchers did not find specific guidelines on how to implement CRTs for grammar instruction in a foreign language context. Whenever possible steps were suggested, no concrete procedure was provided. Another weakness found in the literature is that the steps proposed by Widodo (2006) have not been fully studied by other authors. The implications and the effectiveness of this series of steps have not been evaluated. Therefore, the researchers of this research project evaluated the effectiveness of these steps combined with the characteristics of CRTs in grammar instruction, specifically simple past, past continuous, and present perfect tenses.

The need that this study accounted for is that based on the interviews, most of the English teachers largely rely on textbooks to teach grammar. Therefore, the researchers of this project believed that teachers needed additional strategies to diversify their instruction, assess textbooks, raise students' awareness, and increase students' active participation. For these reasons, CRTs can be useful for high school English teachers because they include a larger repertoire of activities to teach grammar. Moreover, these tasks can benefit students because they were designed to promote awareness of form in a communicative setting. With the methodology proposed in this project, the researchers believe that students can enhance their learning process.

\section{Review of literature}

\subsection{Integration of Inductive and Deductive Grammar Instruction in Language Tasks}

The efficacy of an inductive or a deductive method to teach English grammar has been extensively discussed and compared by various authors throughout time. This comparison has been made by analyzing the impact of providing students with the rule or letting them identify the grammatical structure on their own. According to Shaffer (1989), in the inductive method, it is necessary for learners to codify their own learning and to articulate the target feature, whereas in the deductive method students are provided with the explicit rule.

In the inductive method, the learners' attention is focused on a feature of grammar under study. In this method, learners take an active role. Herron and Tomasello (1992) have stated that during the inductive presentation of grammar, the teacher must involve learners in a meaningful exercise constructed to evaluate if they are noticing and acquiring the target 
feature by hypothesizing about it. For instance, language examples related to the grammar structure are presented at the beginning of the lesson. Students understand the grammatical rules and formulate hypotheses about them based on those examples. In the process of acquiring a foreign language, learners are thus guided to obtain and to store knowledge with the aim of internalizing rather than only memorizing a given rule.

As for the deductive method, Herron and Tomasello (1992) stated that the teacher begins the lesson by describing the rule and providing contextualized exercises where the students have to apply the rule. Decoo (1996) defined deduction as:

the process that goes from the general to the specific, from consciously formulated rules to the application in language use. It evokes the image of the grammar-based methods and of cognitive approaches. In contemporary terminology, it is easily identified with learning. (p.2)

According to Widodo (2006), the assumption that learning a language is related to knowing the rules is encouraged by the deductive method. However, the deductive method prevents that learners internalize the wrong rules. In the deductive method, the students are given the rules; therefore, there is no risk of coming to the wrong hypothesis about it, as it could occur in the inductive method. Thornbury (1999) has stated three principles for the deductive presentation. First of all, the teacher begins the lesson by providing the rules. Afterwards, the teacher highlights the grammar structure in illustrative examples. Finally, learners practice the rule in exercises given by the teacher and produce their own examples at the end of the practice.

Herron and Tomasello (1992) argued that the role of the teacher in the inductive method differs from that in the deductive method. In the inductive method, the teacher is in charge of guiding the learners to hypothesize by themselves about how the target feature of the language is structured. Conversely, in the deductive method the teacher is in control of the lesson and directs the attention of the learners to the target feature by providing the rules and the tasks to apply those rules; this method is teacher-centered. According to Einstein (as cited in Widodo, 2006), learners are in control during the practice in the deductive method because they have less fear of drawing conclusions of how the grammar feature works.

Herron and Tomasello (1992) highlighted the assumption that scholars determine in what way a specific feature of grammar is used when they establish a supposition regarding the essential consistency of a grammar feature during an oral activity. In addition, in their 
study, these researchers found that when given immediate feedback, learners acquire the grammar features more meaningfully than those learners provided with delayed feedback. Therefore, immediate feedback plays an important role in guiding learners to correct themselves and learning the grammatical features. To correct possible errors and to expand the topic studied, the learner has to recognize the error and learn from it.

Erlam (2003) developed a study where she compared the effects of teaching with the inductive and the deductive methods. She concluded that the learners who used the syntactical construction of the structure did worse than the learners who used the inductive method. With the inductive method, the learners improved much more the procedures of construction of the language that evaluated morphology. In the deductive method, the learners were given a list of grammatical rules, and then, they practiced the rules through exercises. This author found that through the deductive method, the learners obtained higher scores in the delayed post-test than the learners who received classes with the inductive method.

One of the advantages of using the inductive method is that students learn and develop autonomy in the learning process. According to Widodo (2006), "The learners are more active in the learning process, rather than being simply passive recipients. In this activity, they will be motivated" (p.128). In fact, the inductive method promotes noticing because the teacher does not describe the grammatical structures. Instead, learners are provided with many examples of how the rules are used. The purpose is that learners notice how the grammatical rules work.

According to Decoo (1996), "The induction will probably take place as described: a slow penetrating of automatisms which eventually will lead to some intuitive rule-formation" (p.12). In the same way, the application of this method is not as fast as the deductive method because learners need more guidance to acquire the knowledge and hypothesize the rules. Learners are guided in and then they lead the process subconsciously and implicitly. Decoo conducted a study that evaluated the effects of teaching grammar deductively and inductively. He did not support either of the two approaches as the best to teach grammar.

Even though there are studies on grammar learning that support the inductive method (Haight, Herron and Cole, 2007; Herron and Tomasello,1992), some researchers such as Hammerly (1975), Adi Ana and Ratminingsih (2012), and Widodo (2006) have promoted the implementation of both methods and the assumption that some grammatical features are acquired more efficiently depending on the method. Hammerly have stated that "there is a 
middle ground in the deduction/ induction controversy. This is to present inductively those grammatical points that the students can learn without an overt rule and deductively, with rules, those grammatical points that require such an approach" (Hammerly, 1975, p.18). The same author proposed the deductive method to teach the grammar features that are not clear after providing some examples and practicing simple exercises. However, teaching grammar inductively has the advantage that learning by discovery leads to better retention than being given the rules.

Adi Ana and Ratminingsih (2012) stated that the inductive and deductive methods for the teaching of grammar have weaknesses and strengths. There is not a perfect method to teach grammar. These authors propose the integration and implementation of both approaches. They created a teaching strategy which combines the strengths of the two approaches to teach grammar to adult learners; it begins with the deductive method and is followed with the inductive method. Widodo (2006) has argued that depending on the structure, some grammatical rules are well suitable for being learned using a deductive or an inductive method. Based on his experience, Widodo created a combination of both methods. He divided it into five step procedures:

Step 1. Building up learners' knowledge of the rule or rule initiation: In this step, the grammatical feature is accessed by the student with the guidance of oral questions provided by the teacher and some model sentences in which the rule is underlined without telling the learner which grammatical rule is going to be learned. The questions can be divided into yes/no questions, information questions, and noticing model sentences. Until the end of the process, the teacher cannot tell the learners the grammatical rule. At the end of this step, the teacher can say the name of the grammatical feature being studied.

Step 2. Eliciting functions of the rule or rule elicitation: The purpose in this step is to provide learners with a specific representation of the grammatical rule by giving them the functions and specific examples of the sentences. The teacher describes the functions of the grammatical feature explicitly. Therefore, the learners can clarify what they did in the previous step by using the rule communicatively. 
Step 3. Familiarizing learners with the rule in use through exercises or rule practice: The aim of this step is the implementation of exercises related to the grammatical feature being taught. In the example provided by Widodo, he used seven exercises:

1. Written question input.

2. Correct verb form completion problem.

3. Sentence transformation problem.

4. Sentence composition problems.

5. Error recognition and correction.

6. Sentence construction or composition based on the tense functions.

Step 4. Checking learners' comprehension or rule activation: In this step, students are asked individually to construct sentences using what they have learned to evaluate their process when applying the rule taught.

Step 5. Expanding learners' knowledge or enrichment: In the final step, the teacher increases the learners' knowledge of the grammatical rule. In this step, the learners can evaluate how much they have learned about the grammatical feature. For the topic studied by Widodo, he proposed two tasks:

1. Pattern identification in a passage or a text

2. Inter-pattern comparison in meaning

In sum, throughout time, researchers in the field of foreign language education have studied the efficiency of the inductive and deductive methods for the teaching of grammar. Both methods have strengths and weaknesses that benefit or hinder the learning of grammar. Some authors such as Adi Ana and Ratminingsih (2012) and Widodo (2006) have suggested the implementation of both methods to maximize their strengths. The inductive method has been favored by some researchers because their studies have shown that when learners discover the rules by themselves, these are acquired more meaningfully. The inductive method promotes noticing, which is part of learning by discovery. However, the deductive method helps learners learn features of grammar that cannot be acquired inductively such as the irregular verbs in English. Therefore, the combination of both methods should be promoted for a better grammar learning. 


\subsection{The Role of Noticing in the Acquisition of Grammar Features}

The noticing hypothesis, proposed by Schmidt, establishes that noticing is necessary for language learning to become input and that awareness must go together with learning. Schmidt (1993) pointed out three main areas that influence conscious and unconscious learning: incidental and intentional learning, attention and noticing, and implicit and explicit learning. Incidental learning and implicit learning are related to unconscious learning. In other words, students acquire a language without being aware of it. On the other hand, intentional and explicit learning are related to conscious learning. That is, students are aware of the language that they are acquiring. Due to the nature of learning depending on the age of the students, noticing can be benefited or hindered. Children acquire language more successfully through incidental learning and implicit learning while adults do so through intentional learning and explicit learning, according to Schmidt.

Schmidt (1993) has pointed out in his theory that attention is fundamental for a language feature to be acquired. This author justified this argument with the work of Logan (as cited in Schmidt, 1993) on attention and psychology. Logan (as cited in Schmidt, 1993) also stated that attention is visualized by most psychological models as a crucial and sufficient factor for encoding information in long-term memory. In addition, the quality and quantity of attention influences language acquisition. Therefore, the learners' attention plays an essential role for achieving noticing. When learners notice a language feature, it becomes intake and acquisition takes place

Furthermore, Schmidt (1993) emphasized one key feature of the noticing hypothesis: "A further extension of the noticing hypothesis is that what must be attended to and noticed is not just the input in a global sense, but whatever features of the input are relevant for the target system" (p. 209). This means that the focus of attention should be on the feature of language that teachers want learners to notice.

Schmidt and Frota (as cited in Schmidt, 1993) did research on noticing and the result supports the noticing hypothesis. They found that when learners compare the correct grammatical pattern and the output that they produce, learners notice the gap. These authors concluded that noticed input becomes intake when learners take part in the process. Therefore, learners should be encouraged to compare the input they are receiving with the output they produce to be involved in the process. In this way, students may be able to notice their possible gaps to understand grammatical rules. Similarly, Swain (as cited in Mahmoudabadi, Soleimani, Jafarigohar, and Iravani, 2015) claimed that noticing occurs when 
"learners are involved in producing output and they realize they are not able to say their intentions because there are gaps in their knowledge. In this way, learners recognize problem areas in their linguistic production and modify their shortcomings" (p. 20). That is to say, students have to focus not only on the input given by the instructor, but also on their output to notice the gap.

According to the noticing hypothesis, features of language must be noticed to be acquired. Schmidt (1993) has suggested that "one important way that instruction works is by increasing the salience of target language forms in input so that they are more likely to be noticed by learners" (p. 217). This means that teachers should emphasize the presence of the target form to attract the attention of learners to that specific feature.

Schmidt and other authors have concluded that noticing is necessary in second language acquisition. For example, Cross (2002) analyzed the factors that can influence noticing. The first factor is instruction, the way in which the teacher guides the process. The second factor is frequency; that is, the more learners are exposed to a feature of grammar, the more opportunities they have to notice it. The third factor is perceptual salience; the more relevant a grammatical form is for the learners, the more their attention is focused on it. The fourth factor is the skill level, the influence of the students learning capacity on noticing. The fifth factor is task demands; tasks should drive students to process the language from low (exchange of familiar information) to high (imaginative and abstract decision making). The sixth factor is comparing; the learners' ability to compare the input given by the teacher with their own output for them to notice the gap.

Another relevant point to take into consideration is that interlanguage can be affected when noticing does not occur. Han and Odlin (as cited in Salas, 2015) argued that "in most interlanguages there is a cessation of learning, known as fossilization" (p. 261). To counter this problem, and according to Salas (2015), "the development of this metalinguistic awareness (noticing the gap) can increase learner autonomy, facilitate the progress of L2 learning, and prevent fossilization: only learners who notice the gap will be able to self-correct and destabilize fossilized errors" (p. 262). This argument supports the relevance of noticing the gap in this research project. 


\subsection{Consciousness-Raising Tasks for Second and Foreign Language Instruction}

One way to teach grammar is through CRTs. For Moradkhan and Sohrabian (2009), CRTs can be seen as tasks in which "instead of being given rules, learners are presented with language data, which challenge them to re-think (and restructure) their existing mental grammar" (p.58). With the implementation of CRTs, students are capable of learning how grammar rules shape the real communication process; thus, avoiding pure memorization and promoting autonomy. According to Ellis (2002), CR can be seen as "an attempt to equip the learner with an understanding of a specific grammatical feature to develop declarative rather than procedural knowledge of it" (p.168). Declarative knowledge is defined as "knowledge about something", while procedural knowledge is "the ability to do things" (Pasternak and Bailey, 2004, p.157). The development of declarative knowledge can help the learners to identify the reason why a grammar structure is used and how that structure works in communication.

To teach grammar features through the use of CRTs involves a series of principles. Ellis (2002) has proposed the following principles: First, having a specific grammar feature to learn can facilitate noticing; teaching only one grammar feature at a time helps learners to acquire grammatical rules, and to focus their attention on that specific grammar rule. Second, students have to focus equally on meaning as well as form to acquire grammar. Recognizing the grammatical meaning of a language and identifying how to apply the grammar rules correctly help students to have a better understanding of the grammar in real life situations. Third, the repetition of a grammar structure promotes its acquisition. The constant repetition and application of a grammar structure in real context by solving grammar tasks can allow learners to understand how that grammar structure works. Last, feedback is relevant in the process. Feedback can be immediate or delayed, including positive feedback or correction of mistakes made by the learners. Additionally, through the given feedback, learners can become aware of their mistakes and the areas for improvement.

Moreover, Ellis (as cited in Idek, Fong, and Sidhu, 2013) hypothesized that CR does not necessarily focus on an immediate correct production of the grammar; instead, CR tries to direct the student's attention to a specific target function (p. 114). In other words, the purpose of $\mathrm{CR}$ is to focus the students' attention on a target feature for them to understand how the feature works without requesting them to produce the target feature correctly since the beginning. This means that $\mathrm{CR}$ serves as a preparation stage where students should be 
aware of the structure studied to integrate this information into their interlanguage in the future.

CR involves an understanding about how students learn a language, how they use it, and how the language works, Roza (2014). This means that CRTs require the students not only to analyze the use of the target feature, but also to understand how the target feature works, leading to a more analytical process for the acquisition of the language.

According to the author, CRTs have several purposes:

1. To direct learners' attention to grammar features they might not notice on their own.

2. To help learners make form-meaning connections.

3. To help learners acquire conscious knowledge which can be used to understand input and monitor their own output. (Roza, 2014, p.3)

The last purpose shows that through CRTs students can understand the input and monitor their own output. This is the most important characteristic, given that it allows for awareness and understanding of the language.

CRTs are also grounded on Krashen's hypothesis of the Monitor Model. Krashen (1982) stated that acquisition and learning work differently. He explained that acquisition is in charge of language fluency because it develops the utterances of a language, while learning works as a monitor or as an editor. The monitor makes changes in the output of the acquired language. This means that the students are able to change their output of the language through learning. In other words, learning enables the students to achieve self-correction that will help the development of fluent language use. Krashen (1982) also proposed that availability of time, focus on form, and availability of explicit knowledge are necessary but not enough for the students to use the rules consciously.

Another relevant feature of $\mathrm{CR}$ is the development of explicit knowledge. Explicit knowledge can be defined as "the kind of intellectual knowledge that people are able to gather about any subject" (Ellis, 2002, p.171). The author explained that even though CR does not lead directly to the creation of implicit knowledge, it promotes its development. For Ellis, implicit knowledge is the knowledge used automatically for communication. That is to say, explicit knowledge is not very useful in communication; instead, implicit knowledge is used, influencing students' fluency directly. In addition, the same author indicates that there are two ways that CR aids the acquisition of implicit knowledge. First, CR prepares students for the integration of new grammatical features because it helps noticing and comparing. 
Second, if students cannot immediately store a grammar feature as implicit knowledge, they can have access to the explicit knowledge when they cannot use the feature automatically. As a result, explicit knowledge leads to an implicit acquisition of the feature. However, Ellis (2002) states that CR has a delayed effect on language acquisition rather than an immediate effect. Similar to Ellis, Sharwood (1981) stated that automatization is how explicit knowledge moves to implicit knowledge. The same author also claimed that if students do not automatize this process after a long period of time, it might be evidence of fossilization. To sum up, CR focuses on explicit knowledge but helps the acquisition of implicit knowledge. This process becomes automatized, but it is not immediate; however, fossilization may occur when explicit knowledge fails to become implicit in the correct form.

\section{Methodology}

This study used a mixed-method approach: quantitative-qualitative with a component of Classroom Action Research. The quantitative analysis was based on a descriptive analysis of the data focused on a systematization of results from the grammar exercises designed for participating students, a diagnostic test, a post-test, and a delayed test in order to assess the effectiveness of the CRTs for the teaching of grammar. The qualitative analysis focused on observations, interviews, questionnaires, and journals for reflection. The project was carried out taking into account methodological aspects from Classroom Action Research in order to retrieve information of each intervention. The Classroom Action Research component was carried out when the researchers were in charge of teaching the class, monitoring learners' performance, reflecting on the outcomes, and proposing strategies to work with consciousness raising grammar tasks in the context of the study. This method is part of the qualitative research method, which has as a primary goal to observe, document, analyze, and interpret characteristics and patterns of the population under study. According to Elliot (1991), the primary aim in action research is the improvement of the teaching practice, rather than the production of knowledge. Based on this idea, it is possible to determine that the use of this method can help the researchers to retrieve information on how to improve teachers' methodology to teach grammar, and in turn, their professional practice as well.

\subsection{Context}

This study was conducted at Palmares Bilingual High School at Alajuela, Costa Rica from April to June 2017. This high school is located in the Palmares County and it was 
founded in 1958. Around 1600 students from different communities of Palmares attend this institution, located in the center of the county. Students spend five English lessons of 40 minutes each per week on reading and writing, five lessons per week on Conversational English, and four lessons of literature. The researchers chose this high school for convenience given that the institution was close to the researchers' residences and for the large number of English classes taught per week in this high school. In addition, the researchers of this project decided to teach verb tenses through CRTs because according to the MEP syllabus (2016), there are verb tenses that are studied in eighth grade and reinforced in ninth grade. Therefore, the students possessed previous knowledge of the different verb tenses.

\subsection{Participants}

\subsubsection{Students}

The students were active participants in the research process and were the main generators of data. The students' parents completed a consent form in order to protect the students' privacy and to allow the researchers to use the information retrieved from the students. The study was conducted with a ninth-grade class during English reading and writing lessons. The researchers selected this group intentionally given that previous knowledge of the verb tenses was required to conduct the study and because the schedule of the group was convenient for the development of the project. The group consisted of a ninth grade class with 10 students, ages between 14 and 15, all Spanish native speakers.

\subsubsection{Cooperating teacher}

The cooperating teacher was in charge of providing a group for the implementation of the project. Also, she was in charge of evaluating the implementation of the Consciousness Raising Grammar Tasks (CRGTs) and observing the lessons. She was an internal source of data because she was familiar with the students' abilities and performance, and therefore, could provide an appreciation about their improvement.

\subsubsection{Researchers}

The researchers guided the research project. There were five researchers involved in the project; three women and two men aged twenty to twenty five. They were in charge of designing and applying the instruments to collect the information from the students and 
carrying out the pedagogical interventions. Additionally, the researchers had to apply the CRGTs, observe how students were developing the tasks, and fill out a journal to reflect on the implementation of the CRGTs.

\subsection{Instruments}

The following instruments were used to collect quantitative and qualitative data.

\subsubsection{Diagnostic test}

The main goal of this test was to select the verb tenses that were taught in the project by identifying the ones the participating students encountered more difficulties with. Based on the results obtained, the researchers selected the verb tenses that were to be assessed through the data collection period via CRTs. This test included multiple choice items. The diagnostic test was applied to all students before the beginning of the research project itself.

\subsubsection{Consciousness Raising Grammar Tasks}

The grammar tasks yielded the data necessary to assess the effectiveness of the CRTs implemented. The grammar tasks consisted of CRGTs (integration of CRTs with the teaching of grammar) that were implemented within a set of strategies proposed by Widodo (2006). The first step of these CRGTs was "Discovering the Grammar": students were provided with model sentences to illustrate the functions of one verb tense at a time, which was bolded. The researchers asked students key questions about the verb tenses of the sentences. The second step was "Learning more about the grammar": some components of the grammar feature were explicitly described; students were then provided with immediate feedback. The third step was "Exploring the grammar": students practiced the use of the same grammar feature continuously with activities in order to familiarize them with the rule. The fourth step was "Playing with the grammar": students made sentences using the grammatical feature based on a given topic and a situation. In this step, the researchers evaluated the students' comprehension by checking the use of the target grammatical feature in the sentences. The last step was "Finding the grammar"; students analyzed a short passage and corrected the mistakes regarding the grammatical feature studied. These grammar tasks were given to the students, one at a time, during each intervention as a form of on-going assessment. 


\subsubsection{Observation sheets}

The purpose of the observation sheets was to evaluate the strengths and weaknesses of each strategy and the students' attitude towards the methodology. These observation sheets contained a series of characteristics of CRTs to analyze the implementation of the methodology. The cooperating teacher and the researchers were in charge of observing the classes and providing feedback to the researchers.

\subsubsection{Post grammar task questionnaire}

The purpose of the questionnaire was to gather data about the perception of the students regarding the application of the CRTs in the grammar teaching. This instrument had one open-ended question and one close-ended question which asked about how difficult or easy to understand the verb tense through the CRGTs was. The students answered the questionnaire after completing each cycle of consciousness raising tasks.

\subsubsection{Journal}

This instrument was used to gather perceptions of improvement and difficulties in the implementation of the strategy. The goal in this journal was to retrieve information about the students' progress during the interventions. This journal was composed by a set of questions answered by the researchers to get qualitative information about aspects to take into consideration during the implementation of the strategy. The researchers completed this journal at the end of each intervention.

\subsubsection{Post-test}

The post-test evaluated the students' knowledge of the grammar feature(s) after the interventions took place; it was based on the diagnostic test, though the post test was constructed only with those sections from the diagnostic test that students had more difficulties with (the ones that were taught in the interventions). The post-test was given to the students after the interventions. The results from the post-test and the diagnostic test were compared to quantitatively determine the degree of effectiveness of the interventions.

\subsubsection{Delayed-test}

The delayed-test evaluated the possible residual impact of CRGTs for the learning of series of verb tenses. The delayed test was constructed with the same number of items for 
each grammar feature as the post-test, using the same format of multiple-choice items. The delayed test was given to the students a month after the interventions. The results from the delayed test were compared with the results from the post-test to evaluate if there was a residual impact of the CRGTs.

\subsubsection{Interview to the cooperating teacher}

This interview was used to gather information of the cooperating teacher's perception about the effectiveness of the CRGTs applied in the interventions. This instrument had openended questions and close-ended questions. The cooperating teacher was interviewed after the interventions.

\subsubsection{Final questionnaire for the students.}

The purpose of this questionnaire was to gather information of the students' perception about the effectiveness of the CRGTs applied in the English grammar classes. This instrument had open-ended questions and close-ended questions. The students completed the questionnaire after the interventions.

\subsection{Analysis of Data and Interpretation of Results}

In regard to the quantitative analysis, the researchers calculated the difference in mean scores between the pre-test, post-test and delayed test per tense and overall to determine the rate of success and residual learning to determine the students' success when performing the task. As for the qualitative analysis, the information retrieved from the observation sheets, journals and post interventions' questionnaire were triangulated with the perspective of students, cooperating teacher, and researchers, concerning the effectiveness of the CRGTs.

\section{Results}

This section contains the major findings gathered through the interventions. This part is organized according to the main sources of data used: CRGTs, the students, the cooperating teacher, and the researchers. In the first section, the results from the diagnostic test, posttest, and delayed test, and the steps in each intervention are shown. The second section contains the students' perceptions of task difficulty across the interventions as well as the results from the final questionnaire. The third section shows the comments of the cooperating 
teacher about task difficulty. In the last section, the researchers' comments in the journals and observation sheets are described.

\subsection{Consciousness Raising Grammar Tasks (CRGTs)}

The diagnostic test was applied to evaluate students' previous knowledge of the basic tenses in English, namely: simple present, present continuous, simple past, past continuous, present perfect, simple future, and future with be going to. The purpose of the test was to choose the three most difficult verb tenses for the students to develop the interventions accordingly. Figure 1 shows the students' average number of incorrect answers per feature on the diagnostic test.

Figure 1

Rate of Difficulty per Grammar Tense in the Diagnostic Test, 2017 (average score)

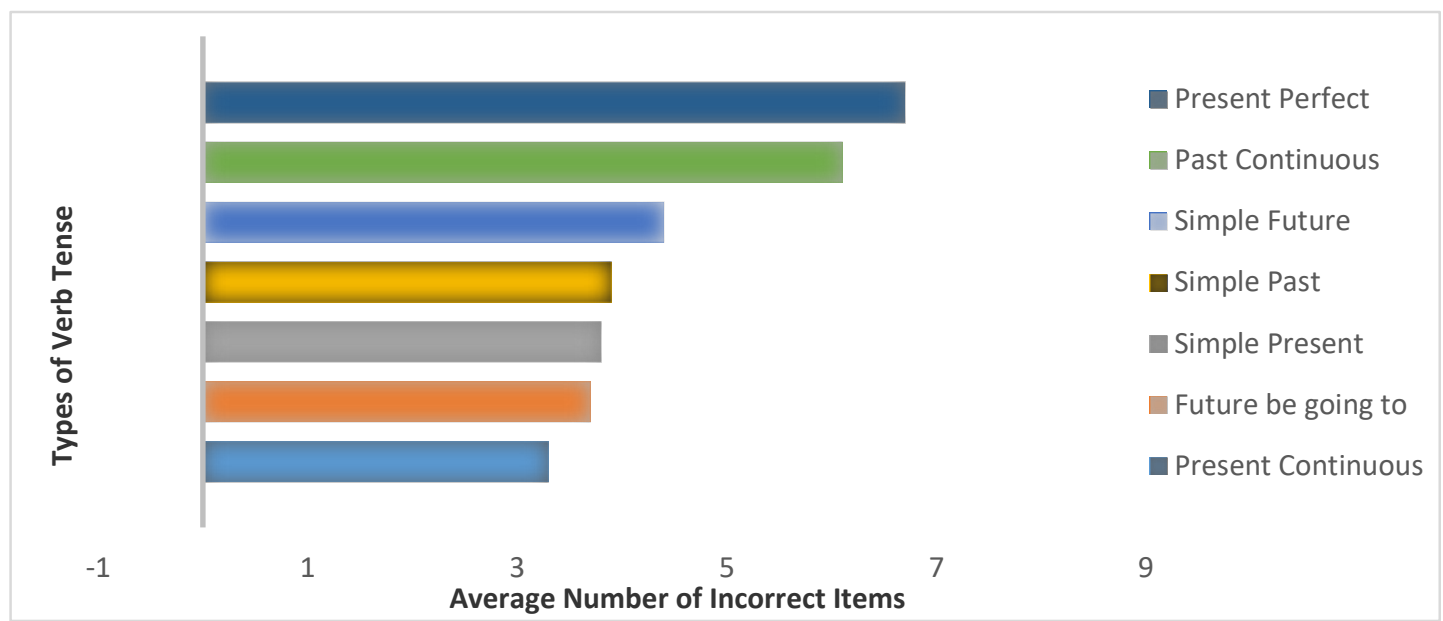

Source: Own elaboration based on the results from the diagnostic test, April $18^{\text {th }}, 2017$.

To make the comparison between verb tenses possible, the researchers evaluated the same number of items per tense, nine. The average score of incorrect answers shows that students made more mistakes in the present perfect with a score of 6.7 incorrect answers out of nine, followed by the past continuous with 6.1 incorrect answers, the simple future with a score of 4.4 , and the simple past with 3.9. The researchers hence selected the simple past, the past continuous, and the present perfect for the study. The purpose of this was to follow an increasing level of difficulty for the tenses and a smooth transition between topics. The simple future was discarded as it fell outside the system of past tenses.

A further comparison was made using the results of the diagnostic test, the post-test and the delayed test. A comparison between the diagnostic test and the post-test was 
developed to determine the effectiveness of the CRGTs. In addition, a comparison between the post-test and the delayed test was made to determine the residual learning of the tenses. The diagnostic test was applied before the application of the tasks, the post-test, after the cycle of interventions had concluded, and the delayed test, one month after the cycle of interventions had concluded. Figure 2 illustrates the comparison of the results between the diagnostic test, post-test, and delayed test.

Figure 2

Average of Correct Answers of the Diagnostic Test, Post-Test and Delayed Test, 2017 (average score)

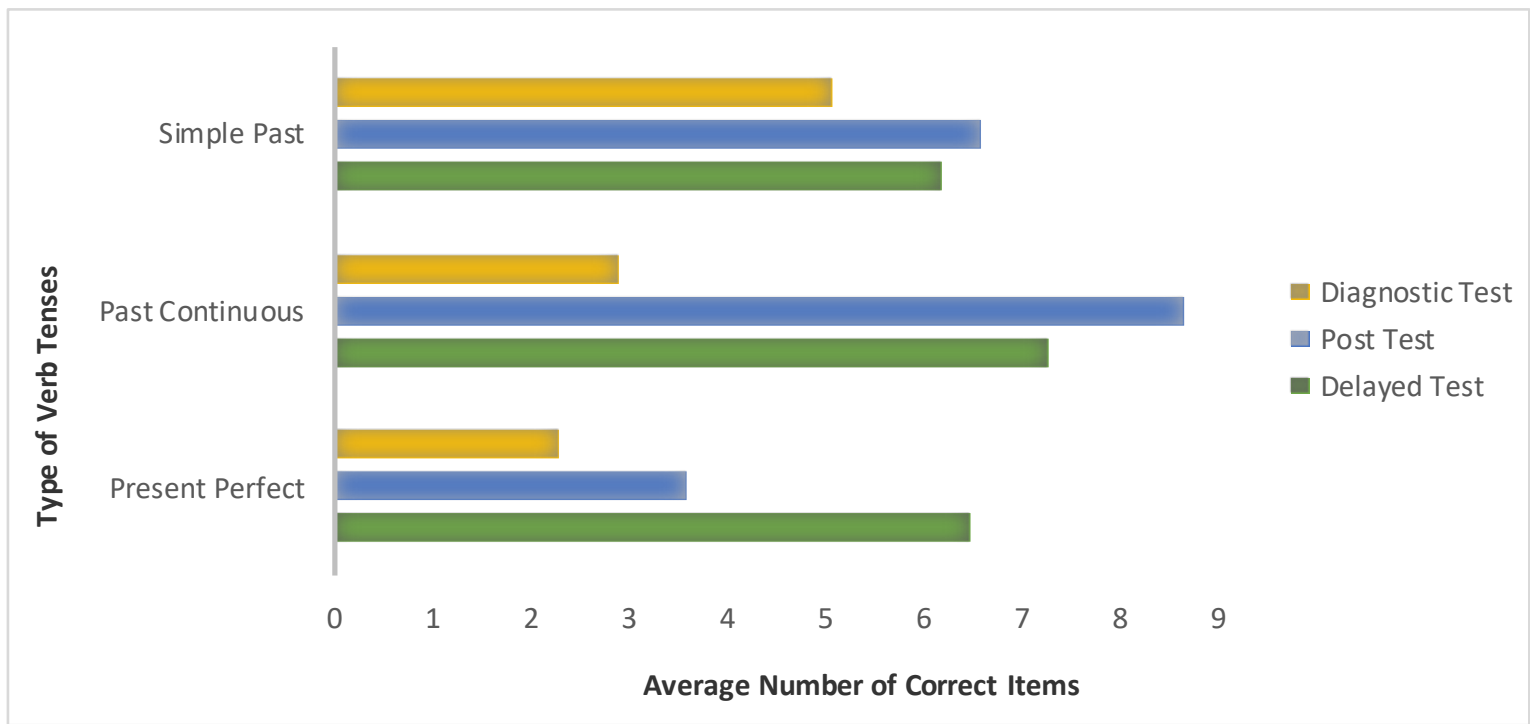

Source: Own elaboration based on the results from the diagnostic test, April 18th, Post-test, June 28th, and Delayed test July 26th, 2017.

In each bar graph in Figure 2, the results of the diagnostic test are placed at the top, the results of the post-test in the middle, and those of the delayed test at the bottom. The average number of correct items in the three tenses clearly increased in the post test as compared to the diagnostic test. The simple past increased from 5.1 to 6.6 correct answers out of 9 , the past continuous from 2.9 to 8.7 correct answers and the present perfect from 2.3 to 3.6. Regarding the delayed test, the results from the simple past and past continuous slightly decreased to 6.2 and 7.3 respectively in comparison with the post-test and the results from the present perfect increased to 6.5 compared to the post test. This increase in the posttest and the delayed test could be related to the fact that the students were able to practice the verb tenses through the CRGTs. As a result, the students may have noticed the 
structures involved in the tenses and become aware of their use. This may have positively affected the performance of the students in the post-test and the delayed test.

\subsection{Students' perception of task difficulty}

The students completed a post-task questionnaire after each intervention to evaluate the perceived difficulty to adapt the CRGTs and avoid exceeding the difficulty of the first two interventions. The simple past was taught in the first and second interventions, the past continuous in the third and fourth, and the present perfect in the fifth and sixth. It is important to clarify that for every tense in the first session the researchers taught affirmative and negative statements of the verb tenses and in the second session, the researchers taught the interrogative structure of the verb tenses. The students graded their perception using a scale from 0 to 10,0 being "very easy" and 10 "very difficult". Therefore, the lower the score, the easier students perceived the task. The researchers applied this post-task questionnaire after each session. Figure 3 shows the perceived difficulty of the CRGTs per intervention.

Figure 3

Average Score of the Perception of Difficulty by Intervention, 2017 (average score)

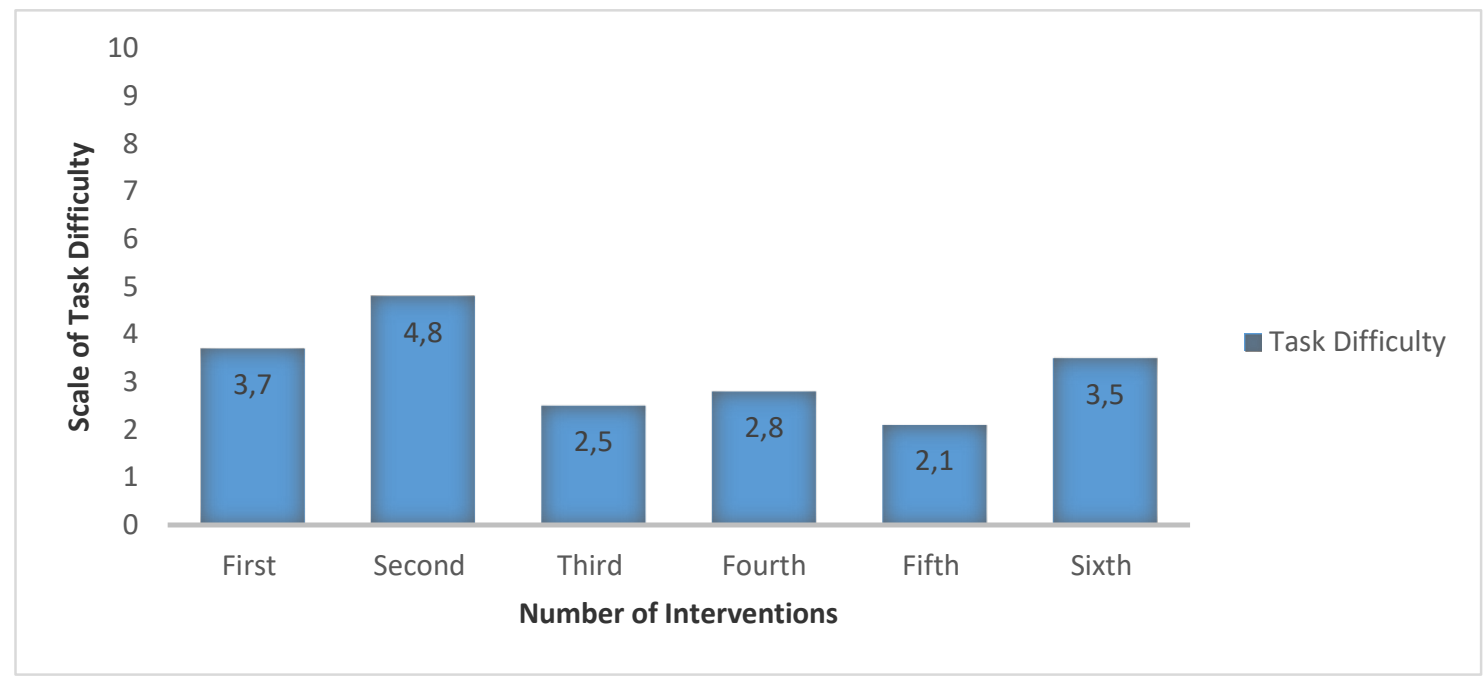

Source: Own elaboration based on the results from the post-task questionnaire applied in the interventions from May $9^{\text {th }}$ to June $20^{\text {th }}, 2017$

As Figure 3 shows, the first two interventions were the interventions with the highest average of task difficulty. After these two interventions, the average score of the students' perception of difficulty decreased. The reason behind this decrease may be linked to the students' progressive familiarization with the tasks. Moreover, Figure 3 shows that students 
had more difficulties with the question structure of the verb tenses than with the affirmative and negative structures. Consequently, it can be seen that the students perceived the CRGTs where the question structure was taught as more challenging than the CRGTs where the affirmative and negative statements were presented. This could be due to the students' having to perform more cognitively challenging tasks and make a greater intellectual effort in the tasks when questions where taught. As a result, the students may have encountered more difficulties in the completion of these tasks. It is relevant to point out that the average score of the students' perception of task difficulty remained below the middle of the scale, which seems to be positive given that students believe that throughout the interventions the tasks did not pose much difficulty for them.

The students also completed a questionnaire at the end of the interventions for the researchers to obtain data about their overall perception of the CRGTs applied in each intervention. The final questionnaire consisted of a series of questions about the steps and application of the CRGTs. Table 1 shows the students' perception of the difficulty of the steps.

Table 1

Students' perception of the steps difficulty in a ninth grade at Palmares bilingual high school, second trimester, 2017.

(nominal value)

\begin{tabular}{|c|c|c|c|c|c|}
\hline \multirow[t]{2}{*}{ Steps } & \multicolumn{5}{|c|}{ Number of students per level of difficulty per step } \\
\hline & Very Easy & Easy & Regular & Hard & Very Hard \\
\hline Step 1: Discovering the grammar & 3 & 7 & 0 & 0 & 0 \\
\hline $\begin{array}{l}\text { Step 2: Learning more about the } \\
\text { grammar }\end{array}$ & 3 & 6 & 1 & 0 & 0 \\
\hline Step 3: Exploring the grammar & 3 & 6 & 1 & 0 & 0 \\
\hline Step 4: Playing with the grammar & 2 & 5 & 2 & 1 & 0 \\
\hline Step 5: Finding the grammar & 6 & 3 & 1 & 0 & 0 \\
\hline
\end{tabular}

Source: Own elaboration based on the results of the final questionnaire for the students, question 9. May $28^{\text {th }}, 2017$.

The results from Table 1 illustrate that the students' perception of difficulty of the five different steps of the CRGTs remained between the categories easy and regular, highlighting that only one student mentioned that step 4 was hard; however, none of the students perceived the steps' difficulty as very hard. Therefore, it can be interpreted that the difficulty of the steps was adequate for the students' level. According to Table 1, the students seemed to have encountered more difficulties completing step 4 since they were required to apply the 
target verb tense by creating new sentences and this process could have required more intellectual effort. As a result, some students could have perceived this step as more difficult.

\subsection{Cooperating teacher's perception of CRGTs}

The cooperating teacher was in charge of evaluating the implementation of the CRGTs by filling out an observation sheet given by the researchers. She perceived that the steps were according to the principles of CR and they fulfilled their main purpose (to raise students' awareness). Also, she felt that throughout all the interventions, the sequence of the activities helped students to understand the grammatical tenses. She expressed that the students managed the grammatical structures of the tenses better because they knew that the structures had a purpose in real life situations. In addition, the cooperating teacher answered that the level of difficulty between steps was more challenging and helped students to build up on their previous learning to continue performing the exercises. Another relevant result gathered from her perception through the observation sheets and the final interview was the task difficulty of the CRGTs. According to the cooperating teacher, the task difficulty of the CRGTs was challenging for the students, but the CRGTs did not surpass the students' English level. In addition, she stated that the students became familiar with the CRGTs through the interventions by completing the tasks with less difficulty.

\subsection{Researchers' perception of the CRGTs}

The researchers followed this type of observation because they explicitly explained the goal of the project to the students and that they were going to be present in every intervention. The criteria observed were the development of the steps and students' reactions towards the principles of CRTs. The researchers performed one observation per intervention, and one different researcher was assigned to observe the class at least once. The researchers perceived that the steps followed the principles of CR and they accurately fulfilled their main purpose. Throughout the applications of the interventions, the researchers noticed that the students became familiar with the sequence of the activities because they were able to complete the tasks with less difficulty. Moreover, the level of difficulty of the activities and the vocabulary were adapted in a way that it could be challenging but without overpassing the students' English level. Finally, in regard to task difficulty, according to the researchers' perception, the CRGTs matched the students' English level, but the CRGTs were challenging for them because the final goal in the tasks was to develop consciousness raising and 
noticing of a specific verb tense by completing a scaffolded series of steps that the students were not familiar with. However, the researchers never perceived that the CRGTs had a high difficulty to be completed.

\section{Discussion}

In this section, the cooperating teacher's, the students', and the researchers' perceptions were triangulated. The perspectives were compared with the theories of the Integration of Inductive and Deductive Grammar Instruction in Language tasks, The Noticing Hypothesis, and Consciousness Raising to evaluate the effectiveness of CRGTs for the learning of one grammatical structure in high school English classes. The triangulation was based on the perception of task difficulty and the perception of the effectiveness of the tasks and their relationship to $C R$.

Concerning the role of input, it was observed that the texts in which the target feature was taught helped the students to become aware of the target grammar feature. The reason for this could be that the input presented in the CRTs included the three principles proposed by Ellis (2002) and Widodo (2006). To begin with, the input focused the learner's attention on one feature by using the noticing strategy of highlighting. Moreover, the input focuses equally on meaning and form because the researchers asked the students questions before and after the presentation of the input to provide context and to guide them to analyze the use and the structure of the target tense within the input. In addition, the feature was used on several occasions within the input to enhance the students' awareness of the feature. However, in spite of the perceived positive effect on the awareness of the grammar feature, the cooperating teacher argued that more examples of the target feature were required to enhance noticing and awareness of it. Even though the cooperating teacher expressed that the input could have been enhanced, this does not guarantee that students would notice the feature studied more easily. As Moradkhan and Sohrabian (2009) stated, students will not necessarily notice a specific feature that is emphasized in the input provided by the teacher. This could be evidenced along the interventions because some students had difficulties answering the questions in step 1 regarding the grammar feature in the input provided. This means that not all the students clearly noticed the feature or were aware of it.

A remarkable characteristic of CRTs is that students have to make an intellectual effort to understand the feature. In the different steps that conformed the CRTs the students had to make and intellectual effort to figure out how the feature worked and why it was used. Even 
though the students had to make an intellectual effort, some students and the cooperating teacher verbalized that two types of activities included in step 3, filling in the blanks and multiple choice, did not demand such an effort. Consequently, the students did not have to strive to understand how to use the feature in context. As a result, these activities did not aid awareness and noticing and should be reconsidered for such a purpose.

Another characteristic of CRTs is that students are required to describe the rule of the target feature. This characteristic was included in step 1 of the CRTs, where the students had to articulate the rule after having analyzed the input. According to Idek, Fong and Sidhu (2013), operational skills, collaboration with peers, and explicit instruction may contribute to students' understanding of the grammar feature. Therefore, after the interventions were carried out, the researchers concluded that more attention should have been given to the students in articulating the rule at the end of the CRTs. In this way, the students could have had the opportunity to develop operational skills, to work with peers, and to receive explicit instruction. As a result, the students would have had a clearer understanding of the verb tenses in question, and thus, would have been able to describe the rules better.

Another finding in this research was that the students and the cooperating teacher expressed, through a final questionnaire, that CRGTs aided them to achieve monitoring because they were able to notice and become aware of their use of the feature in their output. Through the different stages of the CRTs, students had to make an intellectual effort to understand how the grammar feature worked and put it into practice. Therefore, this process seems to have helped them to understand a feature and monitor themselves. According to Krashen (1982), the monitor deals with how students correct their output changing utterances of the acquired language. This means that through the monitor, the students become aware of the target feature and are able to identify mistakes and correct them, which helps the internalization of the feature in their interlanguage. This monitor process was aided with Widodo's proposal because the students learned different mistake categories and how to correct them. As a result, this suggests that the students were able to monitor themselves carefully. To sum up, through CRTs the students had to make an intellectual effort when analyzing the input and to monitor themselves when producing the output for them to be aware of the extent to which they understood the grammar feature presented in the CRTs. 


\section{Conclusions}

During the research, it was identified that the students gradually gained knowledge to describe the different verb tenses as well as to recognize the type of mistakes in a text and correct them and that this seemed to have a long-term effect. The researchers observed, through the results of the interventions and the observation sheets, that the students became familiar with the CRGTs as the interventions progressed. Moreover, the students perceived that the task difficulty was appropriate for their level of English in a way that was challenging but without exceeding their level. This reinforces the importance of conducting a previous assessment of students' knowledge of English before starting the interventions. In addition, this process, where the students had to make an intellectual effort, seems not to have been hindered by task difficulty.

Regarding the strengths found in the project, it was identified that the CRGTs are an active process that encourages critical thinking in students because they have to analyze, compare, confirm, and practice the target feature. This is related to the noticing strategies and the inductive method applied in the CRGTs. On the other hand, one difficulty encountered is that this methodology can be very challenging for students at the beginning because this is not a traditional methodology. This implies that time and extensive practice are necessary. In the research project, the students perceived the first two interventions as the most challenging for them. However, they eventually became familiar with the sequence of steps, which seems to have reduced the degree of difficulty.

After having analyzed the data, the researchers of this project believe that the sequence of the steps was effective to understand a grammatical feature; however, the researchers concluded that step 5 should be done before step 4 . The reason is that in step 4, the students have to produce sentences about the target tense and in step 5 they are required to categorize and to correct mistakes. As a result, this change in the cycle of the steps may help students to notice to what extent they understood possible mistakes found within the target feature and avoid making them in the production of sentences.

As observed in the results from the pre-test and the post-test, there was an improvement in the post-test in comparison with the pre-test. Therefore, it can be argued that the application of CRGTs for the learning of the grammar in high school English classes was effective for the population in the study, fulfilling the goal of this research project. In addition, it was also identified that the acquisition of a grammar feature through the approach which we proposed has a long-term effect because in the delayed test the students kept a similar score 
and even increased this score in the present perfect tense. Moreover, this series of steps can work as a guide for high school English teachers to have a different approach from the ones they typically use in their classes and to encourage CR. Furthermore, the teachers can learn how to develop their own materials without largely depending on grammar books because they will know what sequence to follow and which principles to apply in the development of a grammar task.

Another result is that the steps provided by Widodo (2006) and the noticing strategies seemed to have helped the students to understand a specific grammar feature in context through an inductive and deductive process in secondary English grammar classes. As previously discussed, the aim of the different steps was fulfilled because the students had the opportunity to compare step 1 with step 2 to understand the target tense better. In addition, the steps were boosted with noticing strategies because the students had the opportunity to practice the target tense with multiple exercises adapted to their level. As a result, by following these steps and applying the noticing strategies in an English grammar class, the teacher was able to help the students to better understand the structure and the functions of a grammatical feature and guide them to become aware of the extent to which they had learned the tense and to expand their knowledge.

In this project, further research shall be done to establish if the new sequence of the steps, where step 4 is at the end of the process, is more effective than the sequence of steps proposed by Widodo. Additionally, other researchers are encouraged to do research on the extent to which the steps influence each other and on the relationship between pattern identification and inter-pattern comparison with the ability of self-monitoring in more independent practice. Future research should also be conducted on the cognitive processes behind the different steps of these tasks and how they affect students' performance. It is also recommended that the study be replicated in a larger group and across proficiency levels.

\section{References}

Adi Ana, I Ketut, and Ratminingsih, Ni-Made. (2012). Teaching English Tenses to EFL Learners: Deductive or Inductive? International Journal for Cross-Disciplinary Subjects in Education, 2(2), 998-1004.

Azizifar, Akbar, Babaei, Maryam, Jamalinesari, Ali, and Gowhary, Habib. (2015). The effect of grammatical consciousness raising task on Iranian EFL learners' reading comprehension. Procedia-Social and Behavioral Sciences, 192(1), 252-259.

Cross, Jeremy. (2002). 'Noticing' in SLA: Is it a valid concept? TESL-EJ. 6(3), 1-12. 
Decoo, Wilfried. (1996). The induction-deduction opposition: Ambiguities and complexities of the didactic reality. IRAL: International Review of Applied Linguistics in Language Teaching, 34(2), 95-118.

Elliot, John. (1991). Action research for education change. Philadelphia: Open University Press.

Ellis, Rod. (2002). Grammar Teaching - Practice or Consciousness-Raising? In Jack Richards and Willy Renandya (Eds.), Methodology in language teaching: An anthology of current practice Approaches and Methods in Language Teaching (pp. 167-174). Cambridge: Cambridge University Press. doi:10.1017/CBO9780511667190.023

Erlam, Rosemary. (2003). The effects of deductive and inductive instruction on the acquisition of direct object pronouns in French as a second language. The Modern Language Journal, 87(2), 242-260.

Haight, Carrie, Herron, Carol, and Cole, Steven. (2007). The effects of deductive and guided inductive instructional approaches on the learning of grammar in the elementary foreign language college classroom. Foreign Language Annals, 40(2), 288-310.

Hammerly, Hector. (1975). The deduction/induction controversy. Modern Language Journal, 59(1/2), 15-18.

Herron, Carol, and Tomasello, Michael. (1992). Acquiring grammatical structures by guided induction. The French Review, 65(5), 708-718.

Idek, Sirhajwan, Fong, Lee Lai, and Sidhu, Gurnam Kaur. (2013). The use of consciousnessraising tasks in learning and teaching of subject-verb agreement. English Language Teaching, 6(6), 113.

Krashen, Stephen. (1982). Principles and practice in second language acquisition. New York, Pergamon Institute of English.

Mahmoudabadi, Zahra, Soleimani, Hassan, Jafarigohar, Manoochehr, and Iravani, Hasan. (2015). The effect of sequence of output tasks on noticing vocabulary items and developing vocabulary knowledge of Iranian EFL learners. International Journal of Asian Social Science, 5(1), 18-30

Ministerio de Educación Publica, Costa Rica. (2016). Programas de estudio de inglés: Departamento de Tercer Ciclo y Educación Diversificada. San José, Costa Rica: MEP.

Moradkhan, Dennis, and Sohrabian, Roghayeh. (2009). Grammatical consciousness raising tasks and the improvement of Iranian students' knowledge of grammar. Journal of Teaching English as a Foreign Language and Literature, 1(4), 57-71.

Pasternak, Mindy, and Bailey, Kathleen. (2004). Preparing non-native and native Englishspeaking teachers: Issues of professionalism and proficiency. In Lia D. Kamhi-Stein (Ed.), Learning and teaching from experience: Perspectives on non-native Englishspeaking professionals (pp. 155-175). Ann Arbor: University of Michigan Press. 
Roza, Veni. (2014). A model of grammar teaching through consciousness-raising activities. International Journal on Studies in English Language and Literature, 2(3), 1-5.

Schmidt, Richard. (1993). Awareness and second language acquisition. Annual Review of Applied Linguistics, 13(1), 206- 226.

Salas, Millaray. (2015). Developing the metacognitive skill of noticing the gap through selftranscribing: The case of students enrolled in an ELT education program in Chile. Colombian Applied Linguistics Journal, 17(2), 260-275.

Shaffer, Constance. (1989). A comparison of inductive and deductive approaches to teaching foreign languages. The Modern Language Journal, 73(4), 395-403.

Sharwood, Michael. (1981). Consciousness-Raising and the Second Language Learner. Applied Linguistics, 2(2), 159-168.

Thornbury, Scott. (1999). How to Teach Grammar. Harlow, United Kingdom: Pearson Education Limited.

Widodo, Handoyo. (2006). Approaches and procedures for teaching grammar. English Teaching: Practice and Critique, 5(1), 122-141. 